\title{
Unusual penetrating preauricular injury by firework rocket
}

\author{
Chian-Ze Peng $\cdot$ Chorng-Kuang How \\ Chien-Ying Wang $\cdot$ David Hung-Tsang Yen • \\ Mu-Shun Huang
}

Received: 29 March 2011/Accepted: 9 May 2011/Published online: 22 May 2011

(C) SIMI 2011

\section{Case report}

A 36-year-old young man presented to the emergency department (ED), on Chinese New Year's eve with a stray firework rocket penetrating over the right preauricular region (Fig. 1). He was a bystander on a personal fireworks display. A conical-plastic rocket with attached wooden stick was launched from the ground, which got out of control immediately, and veered horizontally into the crowd. There was not enough time to dodge the flying rocket. A facial computed tomography (CT scan) demonstrated a hypodense linear foreign body entering at the right preauricular area, and tunneled subcutaneously through the superficial parotid region (Fig. 2). Surgical debridement and repair were performed that showed a $0.8 \times 0.8 \mathrm{~cm}$ wound at the right preauricular area, with a stick inside and $4 \mathrm{~cm}$ in penetration to the subcutaneous layer just beyond the ear lobe. In addition, a small inverse $\mathrm{Y}$-shaped laceration at the right ear lobe, and a $8-\mathrm{cm}$ pocket at the postauricular area were also noted. After surgery, he was discharged with an uneventful recovery.

C.-Z. Peng · C.-K. How ( $\square)$ · C.-Y. Wang ·

D. H.-T. Yen - M.-S. Huang

Emergency Department, Taipei Veterans General Hospital, 201,

Sec. 2, Shih-Pai Rd, Taipei 112, Taiwan

e-mail: ckhow@vghtpe.gov.tw

C.-Z. Peng · C.-K. How · C.-Y. Wang - D. H.-T. Yen ·

M.-S. Huang

Department of Emergency Medicine, National Yang-Ming

University School of Medicine, Taipei, Taiwan

\section{Discussion}

The use of fireworks for celebrative purposes is associated with firework casualties. Victims are often male, young and bystanders [1]. Fireworks injuries usually manifest as an explosive or a burn injury. Extraocular penetrating injuries are extremely uncommon [2]. The extent of the injuries is related to the mass, shape, weight of the explosive powder, and the distance traversed. Penetrating wounds by the fireworks associated with the pneumomediastinum and the abdominal visceral injury have been reported previously $[2,3]$. The CT scan has been shown to be useful in the evaluation of the severity of penetrating trauma and the localization of retained foreign bodies. The CT imaging appearance of the wooden foreign bodies is variable. The attenuation of a retained wooden foreign body varies in relation to the content of air and fluid in the interstices of the wood [4]. Dry wood, with a high air content, mimics a gas

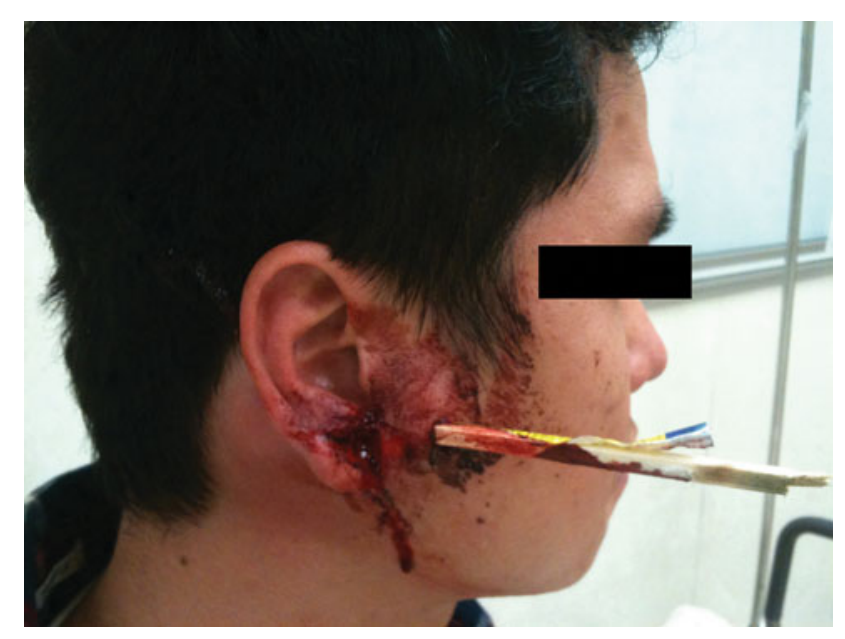

Fig. 1 Physical findings of the patient on admission 


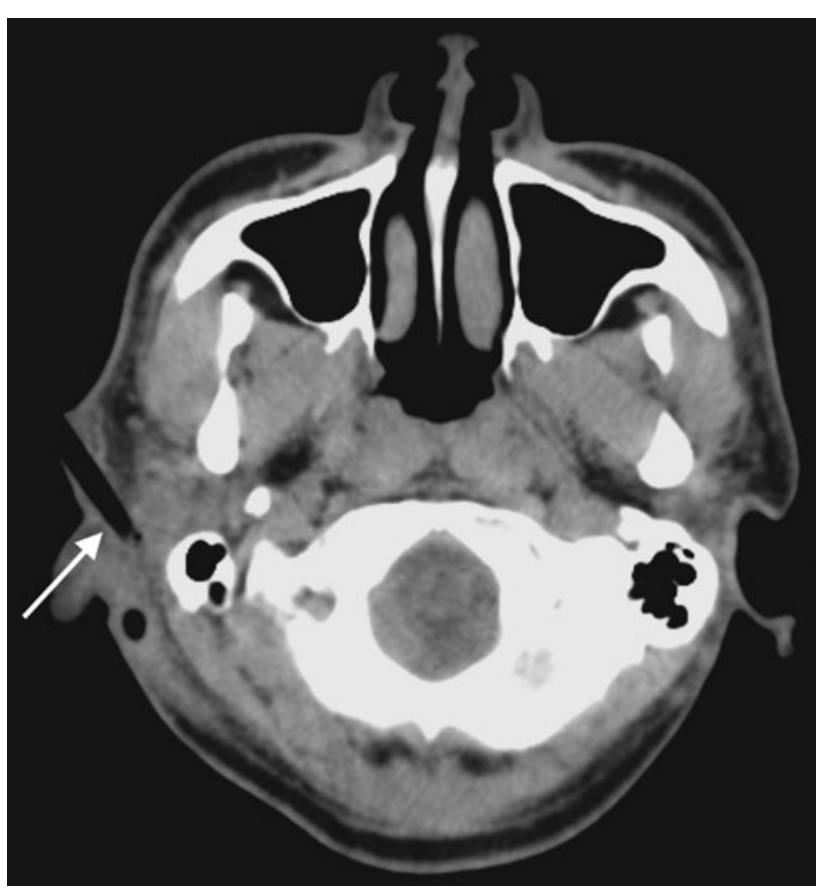

collection. Fireworks trauma should be preventable. Using restrictive fireworks legislation is a proven method to greatly reduce the trauma incidence rates [1].

\section{Conflict of interest None.}

\section{References}

1. Wisse RPL, Bijlsma WR, Stilma JS (2010) Ocular firework trauma: a systemic review on incidence, severity, outcome and prevention. Br J Ophthalmol 94:1586-1591

2. Shakil MS, Smith JEM (1987) Penetrating abdominal wound caused by a firework. Br Med J 295:635-636

3. Matsumura C (1981) A rare case of penetrated sternal wound with pneumomediastinum due to fireworks. Kyobu Geka 34:59-61

4. Peterson JJ, Bancroft LW, Kransdorf MJ (2002) Wooden foreign bodies: imaging appearance. Am J Roentgenol 178:557-562

Fig. 2 Facial CT scan shows a hypodense linear foreign body arrow lodged at the right preauricular region 